\title{
Crítica a las tesis naturalistas de la vida humana. Un diálogo con Hannah Arendt
}

Critique of the Naturalistic Thesis of Human Life: A Dialogue with Hannah Arendt

\author{
CAstor M. M. BARTOlOMÉ Ruiz
} Universidade do Vale do Rio dos Sinos, Brasil

RESUmEn. Desde Hobbes hasta las neurociencias hay una cierta línea de continuidad que tiende a naturalizar la política reduciéndola al gobierno útil de la vida humana, por lo que se transforma en biopolítica. En este marco, la violencia aparece como un instinto natural insoslayable que debe ser administrado políticamente. Contrarrestando el naturalismo de la violencia, y siguiendo algunas pistas críticas abiertas por Hannah Arendt, cabe distinguir entre agresividad y violencia. La agresividad es natural pero la violencia es intencional (simbólica). Ella existe como negación ética de la alteridad y no como pulsión determinante de la naturaleza. Por ello la memoria transciende el ámbito de la mera funcionalidad natural para instituirse como potencia neutralizante de la violencia.

Palabras clave: Violencia, naturalismo, alteridad, memoria, biopolítica.

\section{Prolegómenos de un problema}

La memoria preserva la vida contra la violencia. La vida humana sin memoria se expone vulnerable a la repetición de atrocidades de las que es responsable y víctima. La vida humana, vaciada de memoria, está condenada a repetir sus errores, y cual Prometeo encadenado sufrirá los pesares de su existencia por haber ol-
Abstract. From Hobbes to the new neuroscience there is a continuity which tends to naturalize politics by their reducing it to the governance of human nature, converting it to biopolitics. In this context, violence becomes an unavoidable natural instinct that must be managed politically. Countering the naturalism of violence, and following some critical clues opened by Hannah Arendt, we can distinguish between aggressiveness and violence. Aggressiveness is natural but violence is intentional (symbolic). It exists as an ethical negation of otherness and not as decisive impulse of nature. Thus memory transcends mere natural functionality to be instituted as a neutralizing power of violence.

Key words: Violence, naturalism, alterity, memory, biopolitics.

vidado su pasado. Vida y memoria se coimplican de forma tensa, a veces contradictoria, pero en última instancia la memoria es una garantía para la vida. A veces la memoria (especialmente cuando está atravesada por el resentimiento, el miedo, la venganza, y otras patologías) puede ser su freno, como preconizaba Nietzsche, porque lo paradójico es inherente a todo lo que es humano. Pero no es 
el freno lo que caracteriza la memoria sino su potencia para preservar la vida.

En las sociedades modernas regidas por el capitalismo, la vida humana ha sido objetivada como un elemento útil para el poder. Desde los albores de la modernidad, la vida en general y la vida humana en particular fue significada como una potencia que afecta tanto al poder del Estado como al mercado ${ }^{1}$. La vida dejó el ámbito de la mera responsabilidad individual de la política clásica y se convirtió en objeto de interés público. La vida entró en la política y la política se tornó biopolítica. La entrada en la arena política invistió a la vida de una potencia que antes no tenía, o no le era reconocida. Resignificada simbólicamente como potencia que cualifica la eficiencia del poder, ahora se encuentra atravesada por la condición paradójica de la biopolítica. Lo que posibilita que la vida pueda ser instrumentalizada como un mero medio de producción y objeto de gobierno, o pueda utilizar su potencia para reclamar una dignidad (política) que antes no se le reconocía. Las nuevas luchas políticas del siglo XXI siguen este rastro biopolítico en que la vida se torna una alteridad ética contra los dispositivos de poder que pretenden controlarla ${ }^{2}$. A su vez, esos mismos dispositivos tienden a legitimar la objetivación de la vida como elemento natural (biológico) del que se puede extraer productividad, eficiencia, lucro. Este es el marco tenso de la nueva biopolítica.

El marco biopolítico que busca el gobierno eficiente de la vida humana, delimita y mediatiza cualquier análisis filosófico contemporáneo sobre la vida en general y la vida humana en particular. En él debemos inserir el estudio crítico sobre la violencia y memoria que pretendemos desarrollar.

La violencia es un fenómeno humano complejo. Sus formas son indefinidas, y por ello siempre imprevistas. La imprecisión de la violencia la torna más incisiva y persistente. Lo que hay de común entre todas las formas de violencia es que existen como negación, total o parcial, de la vida humana. En este ensayo proponemos, en un primer momento, analizar algunos espacios de la línea genealógica que conecta la naturalización biopolítica de la violencia desde Hobbes hasta las neurociencias. En un segundo momento presentamos la crítica de Hannah Arendt a la naturalización de la violencia política. Y concluimos con una relectura crítica del naturalismo de la violencia mostrando que no se la debe confundir con la agresividad; que si ésta tiene un marcado carácter natural, aquélla es una construcción intencional, significativa y simbólica.

\section{Naturalizar la vida para legitimar la violencia}

Ya en el siglo XVII, en los albores de nuestra modernidad, Hobbes percibió la estrecha relación que vincula la violencia con el gobierno político. Correlacionando ambos (violencia y política) con una lectura naturalista (mecanicista) de la vida humana. No es casualidad (ni excepción) que la teoría política de Hobbes tenga como substrato la violencia ${ }^{3}$. La necesidad de un poder absoluto se justifica, para este autor, porque la violencia es un elemento constitutivo del estado de naturaleza. Esta condición natural torna la violencia una realidad inherente al comportamiento humano de toda y cualquier sociedad. Desde la perspectiva naturalista de Hobbes, todos los intentos éticos de neutralizar la violencia estarán inevitablemente abocados al fracaso. Para Hobbes, la ética no pasa de una frágil construcción cultural, un débil artificio cultural que poco puede contra la naturaleza. La verdadera política, para el autor, no debe tener por objetivo anular la violencia, algo imposible, sino gobernarla. 
El gobierno de la naturaleza es, tal vez, la marca más característica de la política moderna ${ }^{4}$. El soberano gobernaba por la imposición del miedo, exigiendo la sumisión de los súbditos a su voluntad. Sin embargo, el gobierno moderno establece estrategias para gobernar la voluntad de los otros. Es un gobierno que se caracteriza por la administración eficiente de las tendencias naturales del ser humano, entre ellas la violencia y el miedo. $\mathrm{Su}$ objetivo no es obtener súbditos sumisos, sino administrar las voluntades de las personas y las tendencias de las poblaciones ${ }^{5}$. Gobernar se tornó sinónimo de administrar la naturaleza de personas y poblaciones ${ }^{6}$. Hobbes creó un discurso moderno que inaugura este principio (biopolítico) del gobierno de la vida. La violencia, para el autor, no es un aspecto colateral de la política, sino uno de los elementos constitutivos de la naturaleza humana, y concomitantemente del comportamiento de todas las sociedades. Consecuentemente la política tendrá como uno de sus ejes principales el gobierno útil de la violencia. En esta relación de fines y medios, Hobbes demarcó la importancia del miedo como técnica eficiente para el gobierno útil de las poblaciones.

Desde Hobbes la relación entre violencia y naturaleza se estableció a través de la categoría de causalidad. El siglo XVII y parte del XVIII desarrolló el concepto de causalidad natural en el marco del paradigma mecanicista. Todo comportamiento natural remite a una causa, también natural, que lo provoca y que trae como consecuencia determinados efectos ${ }^{7}$. La sombra de la física de Galileo reinaba sobre las intenciones filosóficas de estos pensadores.

La reducción del comportamiento humano y social a causas naturales transforma la política en una forma racional de administrar la naturaleza humana. Go- bernar bien es administrar con eficiencia las causas naturales que regulan el comportamiento de las personas y sociedades. Nada contra la naturaleza, todo a través de ella. Hobbes, obsesivo en apuntar las causas naturales de la sociedad, percibe la violencia como dimensión constitutiva de la naturaleza humana. Como consecuencia (natural) el miedo se torna la fuerza política por excelencia, ya que: «debemos concluir que el origen de todas las grandes y duraderas sociedades no proviene de la buena voluntad recíproca que los hombres tendrían unos para con otros, sino del miedo recíproco que unos tienen de otros» ${ }^{8}$. La violencia, para Hobbes, no es una excrecencia de la naturaleza, sino la esencia que explica el comportamiento belicoso de las personas y sociedades. Algo que sólo podrá ser refrenado por un poder absoluto en forma de Leviatán, pero nunca neutralizado en su potencia amenazadora. Con esta premisa naturalista, gobernar es sinónimo de administrar la violencia con fuerza y sabiduría. Con la fuerza del poder absoluto del Leviatán y la sabiduría que utiliza el miedo como técnica política para gobernar la voluntad de los súbditos.

Hobbes se tornó un autor maldito para el liberalismo mercantilista, pero, a su vez, la «maldición» de Hobbes fue absorbida por las principales tesis del liberalismo moderno. Entre ellas el principio naturalista de la violencia y la identificación de la política con la administración eficiente de la vida humana. El vacío dejado por la decadencia del paradigma mecanicista fue ocupado por la biología. Nada más natural que la vida, nada más político que conocer las leyes biológicas del comportamiento humano. Esta obsesión constante desde el siglo XVII continúa instigando la búsqueda de una causalidad, cual eslabón perdido de la naturaleza humana, que explique el funcionamiento natural de las sociedades. Lo 
que torna moderna a la modernidad es su obsesión por la noción de causalidad natural. La convicción «casi religiosa» de que la ciencia lo explica todo, que el comportamiento humano es reductible a leyes, que la dinámica social está regulada por principios internos y que la historia tiene una regularidad pasible de conocimiento y previsión, son convicciones modernas.

\section{I}

El paradigma biológico, desde sus orígenes, no ha cesado de ampliar su influencia sobre la explicación causal del comportamiento humano. No es casual que, históricamente, el formato discursivo de la biología moderna sea similar al paradigma hobbesiano. La mirada de Darwin sobre las especies biológicas, contra lo que él pensaba, no veía la objetividad en la naturaleza, ni la neutralidad de los hechos, ni la naturalidad de los elementos, sino que todos ellos eran filtrados por la hermenéutica de Hobbes implícita en su formación académica y moral. No es casual que Darwin viese la competición como causa natural de la evolución, él la llevaba dentro de sí como principio filosófico de la naturaleza ${ }^{9}$.

Actualmente el desarrollo del paradigma biológico persiste en desarrollar nuevas formas de causalidad natural para explicar la sociedad. Tal paradigma no se desarrolla en un solo sentido, pero para el debate que proponemos en este texto hemos de destacar la tendencia (que es hegemónica) que todavía mantiene vigente el principio de la causalidad natural de la violencia.

Naturalizar la violencia significa condenar la vida humana a la perenne violencia. En esta hipótesis, la violencia, explícita o implícita, se transforma en un medio necesario para defenderse del otro, que siempre es potencialmente violento. $\mathrm{Si}$ la violencia es inherente a la naturale- za humana, estamos condenados, cual nuevos sísifos, a su necesario uso instrumental. No podremos pensar la sociedad, la política ni la vida sin la inserción instrumental de la violencia. Naturalizada, se convierte en medio necesario para defender aquello que amenaza: la vida. El otro aparece naturalmente violento, una amenaza de la que debo protegerme.

En la lógica naturalista, el único medio eficiente para oponerse a la violencia natural, es combatir la violencia con más violencia. La violencia mayor es la única garantía frente a las violencias menores. Esta espiral nos condena a vivir indefinidamente bajo la sombra del Leviatán. En este caso, lo único que nos resta es definir los criterios de legitimación de la violencia que deberá imperar como la violencia aceptable frente a las otras violencias inaceptables ${ }^{10}$.

Todos los otros medios (no naturales) pensados para neutralizar la violencia, entre ellos la memoria, parecen efímeros castillos de ideas fabricadas en el aire de las buenas intenciones que se deshacen como humo ante el inevitable naturalismo de la violencia. En esta hipótesis, el miedo continuará siendo la técnica política más eficiente para gestionar los comportamientos de las poblaciones; el control exhaustivo y detallado de la vida se legitimará como medio necesario para defenderla; la excepción que suspende el derecho se tornará el mejor instrumento para mantener el orden que defiende la vida. La vida amenazada por la violencia natural que invade las relaciones sociales reclama una mayor seguridad al precio de una menor libertad. Los nuevos autoritarismos se presentan como defensores de la vida. Hipertrofiando el miedo (a veces inventándolo) obtienen el consentimiento de la sumisión voluntaria de personas y poblaciones. Este cuadro paradójico de la política moderna que amenaza lo que defiende, o defiende amenazando nos obli- 
ga a pensar la posibilidad de otra lógica de las relaciones sociales más allá de la violencia. Para ello habrá que, en primer lugar, desconstruir el pretendido naturalismo de la violencia para, posteriormente, emprender la eficiente (im)pertinencia de utilizar otros medios no violentos para neutralizarla.

\section{Etnología, neurociencia y naturalismo de la violencia}

Uno de los autores contemporáneos que más ha contribuido para mantener y divulgar la tesis del naturalismo de la violencia es Konrad Lorenz. Reconocido estudioso del comportamiento de los animales, premio Nobel de biología, sus estudios dieron origen, incluso, a una nueva rama del saber biológico: la etología. En su obra más divulgada y conocida Sobre la agresión, un pretendido mal ${ }^{11}$ defiende la tesis de que la agresión es un componente natural de la vida y del comportamiento de todas las especies animales, incluido el hombre. Para Lorenz, entre los denominados instintos primarios de la vida, además de los normalmente aceptados (reproducción y supervivencia) hay que incluir la agresividad.

Lorenz no distingue entre agresividad y violencia. A lo largo de su obra ambas categorías se intercambian como equivalentes. Para este autor, todos los seres vivos son agresivos por naturaleza, siendo la agresividad un instinto que contribuye de forma eficiente a desarrollar los otros instintos de la vida. La agresividad sería un instinto natural al servicio de los otros. Él tiene una función positiva, eficiente, para el desarrollo de la vida en todas sus dimensiones. Sin él, los seres vivos perderían la potencia para desarrollar los instintos básicos de la supervivencia. En una referencia explícita a Darwin afirma que la naturaleza desarrolló el instinto de la agresividad como medio necesario para que todos los seres vivos puedan luchar por la supervivencia individual y de la especie $^{12}$. Sin la agresividad los seres vivos se tornarían anodinos, se dejarían vencer con facilidad por las dificultades o por los rivales, y como consecuencia fracasarían en el objetivo primero y principal de todo ser vivo: sobrevivir.

Un segundo aspecto que Lorenz concluye de sus investigaciones es que, dado el naturalismo de la violencia, todas las especies desarrollaron mecanismos biológicos ad intra de inhibición de la violencia contra sus congéneres. El naturalismo confiere a la violencia un potencial destructivo incontrolable. Si la violencia imperase en toda su potencia natural, acabaría destruyendo las propias especies que la utilizan como medio para sobrevivir. El naturalismo de la violencia es un instinto paradójico. Fue creado por la naturaleza para ayudar los otros instintos de supervivencia, pero si no encuentra un medio de ser neutralizado acabará por destruir aquello que fue convocado a estimular: la vida. Según Lorenz, esta contradicción fue resuelta por la propia naturaleza. La única forma eficiente de neutralizar la violencia natural es creando mecanismos naturales para su inhibición. La violencia inherente a la naturaleza sólo puede ser neutralizada por mecanismos creados y desarrollados por la propia evolución natural de la especie. Caso contrario, la violencia se torna imparable y consecuentemente auto-destructiva para la especie.

Lorenz constató que todas las especies vivas, para inhibir el potencial auto-destructivo de la violencia, desarrollaron a lo largo de milenios mecanismos de inhibición ad intra de la propia especie. Esos mecanismos están adaptados a las necesidades de la especie. Durante miles de años esos mecanismos fueron interiorizados en la naturaleza de la especie como medios eficientes, y suficientes, para inhibir la violencia natural ad intra. 
Por ello, por ejemplo, las palomas y los conejos, como tienen poco poder de auto-destrucción desarrollaron pocos $\mathrm{y}$ leves mecanismos de inhibición de la violencia. En cuanto el lobo o los cuervos desarrollaron amplios mecanismos ad intra de inhibición de su violencia porque poseen un alto potencial de destrucción de sus congéneres ${ }^{13}$.

El ser humano es una especie excepcional en muchos sentidos, para Lorenz tal excepcionalidad le creó un problema grave como especie. El ser humano vive una aguda paradoja. Adquirió la capacidad de dominar la técnica, lo que le otorgó un altísimo poder destructivo. Pero la violencia natural inherente a su especie de primate no ha tenido tiempo suficiente para crear y desarrollar mecanismos biológicos ad intra que inhiban esa nueva potencia destructiva. Como los primates tienen bajo poder auto-destructivo, la naturaleza ha desarrollado mecanismos leves y elementales de inhibición de la violencia ad intra ${ }^{14}$. Cuando el ser humano adquirió el poder destructivo de la técnica, se tornó para la naturaleza un engendro, un Frankenstein de la evolución. Es como un conejo con boca de lobo, o una paloma con pico de cuervo que puede matar de dos picotadas a cualquier congénere sin poder evitarlo porque su instinto violento está altamente desarrollado y no puede inhibirlo. Somos chimpancés con armas automáticas. "Los mecanismos del comportamiento instintivo sin duda no estaban en condiciones de afrontar las nuevas condiciones creadas inevitablemente por la cultura desde sus albores» ${ }^{15}$. El instinto natural de la agresividad de nuestra especie nos impele a tener una altísima dosis de irritación y enfrentamiento, sin que hayamos desarrollado medios para inhibirla. Por ello somos la especie más peligrosa para nosotros mismos.

La indistinción conceptual entre agresividad y violencia lleva a Lorenz a afirmar la tesis de que ambas son instintos naturales. Él afirma que dada nuestra incapacidad natural de inhibir la violencia ad intra tuvimos que crear códigos morales, valores, comportamientos éticos y religiosos como único medio (cultural y simbólico) de intentar frenar la irrefrenable violencia natural. Pero dado que todos estos medios simbólicos no están interiorizados en la naturaleza humana, vivimos la tragedia de ser autores y víctimas de una violencia natural que no podemos evitar y de la cual queremos librarnos siempre. Según Lorenz, no hay solución ni salida definitiva para la agresividad o violencia natural, ya que ella es inherente a la naturaleza humana. Todos los medios culturales que inventemos serán frágiles obstáculos que el instinto natural derriba con facilidad.

Las tesis de Lorenz replicaron ampliamente en otros discursos y autores contemporáneos que a pesar de sus diferencias conceptuales, mantienen la tesis de que la violencia es un instinto inherente a la naturaleza humana con una función socialmente útil. Una especie de funcionalismo utilitarista que actúa como marco conceptual de los nuevos discursos biológicos que naturalizan la violencia. Edward Osborne Wilson dio continuidad a las tesis de Lorenz con sus estudios sobre sociobiología. En su obra más popular Sociobiología. La nueva sintesis ${ }^{16}$, defiende la tesis de que la biología es la ciencia por excelencia que explica la naturaleza humana. Wilson, como Lorenz, no distingue entre agresividad y violencia, considerando que ambos conceptos remiten a un mismo y único instinto natural ${ }^{17}$. El cerebro tomó el lugar del alma humana. La química del cerebro responde por los estados emocionales, incluida la agresión y violencia. Neurotransmisores como dopamina, norepinefrina, serotonina, gaba, son los responsables por la modulación de las emociones, 
estimulando o inhibiendo su funcionamiento. El origen y funcionamiento de la agresividad y violencia estarían conectados al funcionamiento de estos neurotransmisores. Ellos son la explicación última y primera de las alteraciones comportamentales y de los trastornos mentales. Para la neurociencia, como para la siquiatría, las respuestas a la violencia humana se encuentran en la química y sus relaciones con los neuro-transmisores, hormonas y genes. De tanto mirarnos entre las otras especies animales, hemos de concluir que somos una más, sin más. Esta es la máxima de la sociobiología ${ }^{18}$.

Otro exponente de esta corriente discursiva es Richard Dawkins. Sus estudios sobre etología, biología, genética y neurociencia le valieron un amplio reconocimiento internacional. Sus tesis alcanzaron gran divulgación especialmente con su obra El gen egoísta ${ }^{19}$. Para este autor los genes contienen la clave del comportamiento de cada ser vivo. Los genes son máquinas de supervivencia que guían la conducta de los seres vivos. El objetivo al que tienden los genes es su replicación. La estrategia que utilizan es siempre el egoísmo: «este egoísmo de los genes generalmente originará egoísmo en el comportamiento individual» ${ }^{20}$. Incluso, afirma el autor, las actitudes altruistas y las formas de socialización no pasan de estrategias de los genes egoístas, que piensan que vivir en grupo es más provechoso que hacerlo individualmente. En tal hipótesis, el gregarismo (y la socialización humana) son consecuencias del cálculo egoísta de los genes.

Dawkins advierte que la palabra egoísmo es una mera metáfora, pues en biología el comportamiento está regido por leyes naturales y no por valores morales ${ }^{21}$. El objetivo principal de un ser vivo es la replicación y para ello se vuelcan todas las estrategias de sobrevivencia. La replicación de los genes es, para
Dawkins, lo que podemos denominar de egoísmo natural.

Dawkins evita caer en un determinismo naturalista del comportamiento humano. Para ello afirma que en el ser humano además de los genes actúan los memes ${ }^{22}$. Los memes corresponden a una especie de memoria natural. Ellos no son un privilegio de los humanos, también en otras especies vivas como los primates y las orcas, por ejemplo, existen memes, aunque no alcanzan el grado de desarrollo que en los seres humanos. El meme es la memoria constituida por el conjunto de experiencias culturales adquiridas y transmitidas de una generación a otra. El lenguaje es uno de los principales factores que potencia los memes y a su vez estimula el cerebro. A pesar de nuestra naturaleza egoísta, los memes nos ofrecen la posibilidad de mudar artificialmente nuestros padrones de vida y conducta. Según Dawkins, la cultura no es exclusiva del ser humano, pero la memoria y la capacidad de previsión sí ${ }^{23}$.

Para Dawkins la violencia forma parte de la estrategia funcional de la replicación de los genes. Siendo un instinto natural de la vida, no tenemos como neutralizar su pulsión natural, sólo debemos aprender a dirigirla para los objetivos correctos. Una especie de violencia racional. Dawkins, como Lorenz y Wilson no hace distinción entre agresividad y violencia, lo que, una vez más, torna ambas una insoluble amalgama de naturalismo y cultura.

En estas tesis biológicas de la neurociencia adquieren nuevo vigor los argumentos clásicos de Hobbes y Spinoza sobre el naturalismo del comportamiento humano. El autómata del siglo XVII ha sido substituido por el paradigma genético, hormonal y neurológico. Todavía se podrían mencionar otros autores de reconocido prestigio en nuestra contemporaneidad como Antonio Damasio cuyos es- 
tudios sobre neurociencia vienen adquiriendo amplia resonancia internacional en obras como El error de Descartes, o En busca de Espinosa ${ }^{24}$. Las emociones y sentimientos son regulados por la anatomo-fisiología cerebral. Neurotransmisores, sinapsis, hormonas, áreas cerebrales, componen las bases de las emociones y sentimientos ${ }^{25}$. Establece una cierta taxonomía de las emociones, para mejor comprenderlas, teniendo como base las reacciones neurológicas. Los sentimientos, para Damasio, son informaciones que los seres biológicos son capaces de sentir en las situaciones que viven. El miedo es una información sobre el riesgo, la amenaza, el peligro para el propio ser o sus intereses. La neurociencia permite establecer una arquitectura de nuestras emociones y sentimientos con base en el conocimiento del cerebro y su funcionamiento. La violencia se torna un elemento funcional cuya explicación última remite a una base biológica que encuentra en el cerebro el enigma de su solución.

\section{Hannah Arendt, sobre la violencia}

El conatus que Hobbes identificó como elemento de la causalidad natural del comportamiento humano fue abierto cual caja de Pandora y de él surgieron elementos, funciones, neurotransmisores, sinapsis, hormonas, genes... Aunque algunos de los actuales teóricos de la violencia natural no se propusieron elaborar una teoría política, los principios naturalistas que ellos mantienen replican constantemente en la legitimación de prácticas políticas como la de la guerra preventiva, el derecho del enemigo, los dispositivos de control, las formas de excepción, entre otras. Lo que nos obliga a reconsiderar críticamente las implicaciones políticas de los presupuestos naturalistas de la violencia y la validez de tales supuestos.
Antes de iniciar la crítica de los mismos, es conveniente afirmar que no se puede negar la base biológica que condiciona el comportamiento humano. Somos seres biológicos, animales de una especie determinada, y como tales sometidos a las leyes y condicionamientos del tsunami de la vida. Sin duda que todos los ramos de la biología, en especial la neurociencia, abren ventanas epistemológicas importantísimas para comprender mejor el material genético de nuestras decisiones. Cualquier lesión o estímulo en la red de neurotransmisores afectará al conjunto de la personalidad, las emociones, sentimientos el comportamiento. No hay duda que zonas de nuestro material biológico y genético son corresponsables de espacios de la personalidad, dimensiones del comportamiento, vivencias, emociones y sentimientos. Su funcionamiento, correcto o no, afectará de una o de otra forma nuestro modo de ser y al conjunto de la sociedad. La cartografía detallada de nuestro genoma, el conocimiento de nuestro mapa neurológico, aprender a navegar en el laberinto de trillones de sinapsis es de vital importancia para conocer mejor la base material, biológica, de nuestra personalidad. En ello encontraremos muchas explicaciones sobre nosotros mismos y nuestra sociedad. La biología nos abre enigmas de nuestro propio ser. El cuestionamiento que surge es si ella puede explicar de forma total el comportamiento humano. Si la explicación natural puede objetivar la complejidad humana en causalidades naturales previsibles.

La cuestión que se coloca es tan antigua como la propia filosofía de Demócrito y Epicuro, y tan clásica como los modernos Hobbes y Espinosa: ¿es posible reducir el comportamiento humano a su base material, biológica? ¿Es posible explicar bajo el principio de causalidad natural biológica todo el comportamiento 
humano? Concretamente, debemos interrogarnos, ¿es posible reducir, inducir o deducir el ser de la violencia de un supuesto instinto natural o de reacciones químico-neuronales?

El debate sobre el naturalismo de la violencia ha tenido muchas contribuciones a lo largo de la historia. Para nuestro objetivo, nos parece pertinente recuperar parte de la reflexión que Hannah Arendt hizo sobre la violencia en su escrito de este mismo título: Sobre la violencia ${ }^{26}$. Arendt se propone debatir en esta obra, entre otros puntos, la naturalización de la violencia. El motivo que instiga el debate son las tesis sobre la legitimidad de la violencia revolucionaria como parte de la violencia natural. Estas tesis ampliamente desarrolladas por George Sorel en su obra Réflexions sur la violence (1908), y en la década de 1960 otros teóricos de la revolución como Pareto y Fanon defendían, con amplio eco social, el derecho a la violencia con el argumento de que la violencia es natural, inherente a las relaciones sociales de dominación y constitutiva de toda la sociedad. Consecuentemente, a los oprimidos no les resta sino utilizar la violencia como medio político legítimo para sus objetivos de emancipación.

En el tercer ensayo de la mencionada obra, Arendt también cuestiona la naturalización de la violencia emprendida por los discursos provenientes de la biología y la zoología 27 . Ella percibe la línea naturalista que vincula la biología con la filosofía política contemporánea, a través de la cual se legitima la violencia como un dato natural de todos los seres vivos. En ellas se registran los ecos e influencias de las filosofías vitalistas de Nietzsche e incluso de Bergson.

Hay una línea de pensamiento que une la biología a la filosofía política y tiende a vincular la naturalización de la violencia como una especie de pulsión de la vida. En ellas se registra el intento de interpretar la violencia como parte de la potencia de la vida. Es fácil reconocer en estos pensadores los ecos de la filosofía vitalista de Nietzsche, así como su correlativa naturalización de la violencia. Sorel, concretamente, se inspira en el concepto de elán vital de Bergson para considerar la violencia como un elemento productivo de la vida y la sociedad ${ }^{28}$. Para Sorel, la clase trabajadora sería esa una nueva pulsión de vida con potencial para desestructurar la mediocridad burguesa que impuso el capitalismo como sistema de injusticia social. Tal potencia vital e histórica de la clase trabajadora se manifiesta en su capacidad revolucionaria de transformar el capitalismo. Para Sorel, el trabajador es un creador de nuevas cualidades morales necesarias para el nuevo modelo productivo. En este contexto de vitalismo histórico, la violencia es el medio natural a través del cual la potencia creativa de la clase operaria concretizará la transformación del capitalismo.

Arendt afirma que en la relación que Sorel estableció entre violencia y vida, se anticipó a Konrad Lorenz. Pues antes que Lorenz descubriese la función positiva que la violencia tiene para los seres vivos, la violencia ya era elogiada por Sorel como manifestación de la fuerza de la vida y por su potencial creativo ${ }^{29}$. Según Arendt, antes que Lorenz, Sorel ya había establecido una relación entre la pulsión biológica y la violencia, inspirado en el élan vital de Bergson.

Arendt critica el pretendido naturalismo de la violencia. Entre otros argumentos, propone algunas distinciones conceptuales. Propone distinguir entre fuerza, autoridad, poder, potencia y violencia. Defiende que el concepto fuerza quede fuera del vocabulario político y se aplique exclusivamente a las fuerzas de la naturaleza ${ }^{30}$. Autoridad es un concep- 
to al que Arendt vincula un sentido moral, el reconocimiento de la autoridad moral de alguien ${ }^{31}$.

La distinción más aguda que la autora propone es entre poder y violencia. Para Arendt, ni uno ni otro son fenómenos naturales. No pertenecen al proceso biológico de la vida sino al terreno político de las decisiones humanas ${ }^{32}$. El poder, para Arendt, es inherente a la acción política, mientras que la violencia es la negación de ambos (acción y política). La autora define el poder en su forma extrema como: todos contra uno, indicando el origen político del poder y su carácter netamente colectivo. A su vez la forma extrema de violencia se caracteriza por el axioma: uno contra todos ${ }^{33}$. En la lógica de la violencia desaparece el carácter político de la acción. La violencia se torna una forma pervertida del ejercicio del poder, lo que impide identificarlos como sinónimos.

Para Arendt el principal elemento que distingue la violencia y el poder es el carácter instrumental de aquélla. Para la autora, el poder establece los fines de la acción en tanto que la violencia se reduce a un mero medio instrumental para la realización de los fines. Para ella, el poder se define por la posibilidad de actuar colectivamente. Sólo existe poder en la acción colectiva de los sujetos. En tal hipótesis, es impropio hablar de poder individual de un sujeto ${ }^{34}$. Por ello, no ha de identificarse el poder con la estructura social, económica, cargo político, estatus, etc. El poder es aquello que hace posible todas ellas. Para Arendt, el poder es la finalidad a la que tiende la acción social. Lo que equivale a decir que toda acción política tiende a construir una forma de poder, o sea, un tipo de gobierno o formas de relaciones sociales. La hipotética pregunta sobre la finalidad del gobierno no tiene sentido porque el poder no necesita justificación ya que su ejercicio es inherente a la comunidad política. Lo que el poder necesita es legitimidad ${ }^{35}$. La justificación del poder es inherente al ejercicio de la política y ella se da en la acción conjunta de dos o más personas. Sin embargo, su legitimidad deriva del proceso que instituye las formas de poder. La legitimidad remite a un acto pasado en que se origina el poder, en cuanto su justificación apunta para un fin futuro.

La distinción entre justificación y legitimidad permite a Arendt concluir que la violencia, siendo un medio instrumental y nunca un fin, "puede ser justificable, pero nunca legítima» ${ }^{36}$. Su justificación pierde sentido (se torna injustificable) en referencia al fin que pretende (que es siempre la negación de la política, del poder). Aunque en algunos casos la violencia pueda ser justificada, ella nunca será el fin del poder ni el objetivo de la política. Su ilegitimidad es proporcional a la distancia que la separa de la finalidad social del poder y de la política.

La combinación de poder y violencia es fruto del uso estratégico de la violencia por parte del poder, que la utiliza como medio para una finalidad. Arendt destaca que el carácter instrumental de la violencia hace que ella se constituya en un medio para alcanzar la potencia del dominio absoluto sobre el otro ${ }^{37}$. En la violencia extrema, y sólo en esos casos, ambos (medios y fines, violencia y poder) coinciden porque el poder pierde su finalidad (política) y queda absorbido en la mera instrumentalidad de la violencia extrema como forma de gobierno. Cada vez que el poder usa la violencia, ésta pone en cuestión la justificación del poder. Aquélla, que siempre es ilegítima porque no puede tener una finalidad propia, raramente se torna justificable y como consecuencia torna injustificables los actos violentos del poder. Una cuestión grave es saber cuando la violencia es justificable. Lo que nos remite a la pre- 
gunta: ¿cuándo el poder puede hacer uso justificado de la violencia? Esta cuestión es más melindrosa porque en la mayoría de los casos los criterios que justifican la violencia son puestos por el propio poder.

\section{Agresividad y violencia:}

la significación simbólica de la acción humana

Los análisis de Hannah Arendt abren pistas importantes para la crítica al naturalismo de la violencia que deben ser profundizadas. La autora, más allá de las evidencias biopolíticas de la barbarie nazi, percibe con mucha claridad el marco de la biopolítica moderna que tiende a reducir la política a categorías biológicas ${ }^{38}$. Arendt capta el marco biopolítico de la violencia, o sea, el intento permanente de gobernar la vida humana como mera vida biológica a partir de supuestas leyes naturales que regulan el comportamiento de los individuos y las sociedades ${ }^{39}$.

Siguiendo la metodología por ella iniciada, proponemos hacer otra distinción conceptual entre agresividad y violencia. Esta distinción es decisiva para poder dialogar críticamente con los discursos biológicos y la neurociencia.

Hay una diferencia cualitativa entre agresividad y violencia, que pasa desapercibida en los discursos naturalistas. Ella estriba en que si la agresividad tiene un cierto carácter natural, la violencia es siempre una significación intencional, un sentido (simbólico) dado para la acción agresiva.

Como apuntan los estudios de la etología, biología y neurociencia, entre otros, existen pulsiones agresivas inherentes a todos los seres vivos que, además, están insertadas en una lógica funcional de supervivencia de los individuos y de la especie. Estas pulsiones, sin duda, se manifiestan en el ser humano ${ }^{40}$. El punto ciego sobre el que pasan desapercibidamente todas las tesis naturalistas es la potencia creativa del ser humano. Su poder, inexorable, de instituir sentido con todo lo que se relaciona. No hay relación humana sin creación de sentido. El punto de ruptura entre la línea plana de la continuidad biológica de la pulsión y la especificidad de la acción humana es la creación significativa. Lo que diferencia la acción humana del mero acto animal, determinado por la pulsión natural, es que en el ser humano todas las pulsiones pasan por el filtro del sentido y la valoración. O sea, las simboliza con un significado no natural. Ellas, que persisten en el ser humano como pulsiones, se manifiestan en forma de lenguaje, es decir de creación simbólica de sentidos para todo lo que sentimos, pensamos y decidimos. No existe pura pulsión natural en la acción humana. El instinto, la pulsión, cuando aparece en el ser humano, es siempre significada simbólicamente ${ }^{41}$. En contrapartida, también podemos afirmar que ninguna acción humana está exenta de la influencia de las pulsiones biológicas. Las pulsiones vitales e instintos naturales están en el substrato de la creación humana, pero no la determinan. Hay una diferencia cualitativa entre influencia y determinación, que torna la acción humana algo específico, creativo y no un mero acto instintivo. Sólo en las patologías extremas la pulsión natural y la acción humana coinciden. En esas circunstancias vemos al ser humano reducido a mero comportamiento animal.

La acción humana se diferencia del acto animal porque tiene el poder de recrear significativamente el acto. El acto animal es dirigido por las pulsiones, determinado en su finalidad por la naturaleza del individuo. La acción humana es condicionada por aquéllas pero no determinada en su finalidad. El ser humano es tal porque está abierto para alteridad, porque tiene el poder de confrontarse con la alteridad de su naturaleza y no ser un 
mero objeto de sus pulsiones. La abertura para la alteridad le confiere la potencia para definir la finalidad de sus acciones. Sin estas dos condiciones: alteridad y significación, el ser humano perdería tal condición y quedaría relegado a otro tipo de especie animal, lo que no se confirma por los hechos.

El ser humano tiene la potencia de instituir valoración a sus impulsos naturales transformándolos en praxis creadora y no en meros actos reproductores de los instintos naturales ${ }^{42}$. El ser humano es el único ser vivo que puede imponer un sentido a sus pulsiones confiriéndolas una finalidad más allá del instinto. Tal condición torna toda acción humana una acción valorativa, es decir, una acción ética de la que se es responsable y no un mero acto inconsciente de su naturaleza. La graduación entre una y otra, entre la capacidad intencional de significar la propia acción, o el ser llevado por el mero impulso natural, es lo que marca la diferencia entre humano y animal; entre el mero animal humano y la capacidad humana de conducir su existencia; entre la mera vida natural (biológica) y la vida política.

La acción humana es siempre valorativa. En ella se refleja el poder del lenguaje, que se manifiesta como potencia creadora de sentido. Al simbolizar valorativamente los instintos, el ser humano los transforma de meras pulsiones naturales en praxis cultural. Una tensión agónica recorre la acción humana que transforma su naturaleza biológica en una subjetividad histórica. La tensión agónica da la abertura para la alteridad y la creación de sentido se desliza cual potencia transformadora de los condicionamientos naturales de su ser y las posibilidades reales de su existir. La violencia es intrínsecamente afectada por esta doble condición humana: alteridad y creación. Ella confronta al sujeto con el otro ser humano y le desafía a pensar el sentido de la real-acción que va a impetrar. La violencia, atravesada por la mirada del otro que me interpela, pierde su pretendida naturalidad compulsiva y cuestiona el sentido de mi acción. Ella, desenmascarada por la alteridad herida del otro, no puede esconderse más bajo el manto de la falacia naturalista. La violencia sin máscaras muestra su real condición de producción simbólica de sentido.

Podemos concordar con las tesis naturalista que la agresividad es una pulsión natural que existe en todas las especies vivas, incluido el ser humano. También es posible entender que la agresividad tiene una cierta funcionalidad. Pero ni una ni otra se imponen de forma determinista a la acción humana. La agresividad no necesariamente tiene que derivar en violencia, ni su funcionalidad significa uso estratégico de la destrucción del otro. Ambas dimensiones pueden ser significadas por el ser humano y la sociedad para hacer de la agresividad una forma de relación constructiva y no destructiva. $\mathrm{La}$ agresividad natural no se impone como violencia necesaria.

\section{Violencia: acto intencional y negación de la alteridad humana}

¿Qué distingue la agresividad de la violencia? Esta cuestión nos remite al carácter específico de la violencia: la negación de la vida humana. La violencia tiene una finalidad específica que la distingue de la mera agresividad. Tal finalidad requiere la intencionalidad explícita del sujeto, que pretende negar la alteridad del otro ser humano.

La violencia existe como acto intencional con objetivo de negar, total o parcialmente, la alteridad humana. Tal definición nos permite circunscribir la violencia en el espacio específico en que manifiesta su brutal potencia: la destrucción de la vida humana. 
La violencia se caracteriza por ser un acto intencional y no meramente natural. La intencionalidad es constitutiva de la violencia, y de toda acción humana. En su caso específico, la intencionalidad que identifica la violencia como tal es la destrucción del otro. La violencia es concomitante a la producción de las víctimas. En toda violencia hay una intencionalidad significativa que torna tal acto humano y no meramente animal. Por ello toda violencia, antes que un acto natural, es una violación ética. Lo que define la violencia no es la influencia de las pulsiones agresivas (propio de la agresividad), sino intencionalidad de violentar la relación ética con el otro. Podemos decir que los animales son agresivos y que sólo el ser humano es violento. Tenemos el privilegio de poseer la potencia de la significación simbólica de nuestras acciones y por eso la responsabilidad ética de lo que hacemos.

La violencia no se limita a ser un mero medio para otros fines, sino que ella se caracteriza por (con)tener una finalidad propia: la intención de destruir, total o parcialmente, al otro. Esa finalidad implícita a la violencia la substrae de la mera condición de medio y la torna, también, una acción con finalidad propia. Aunque la violencia puede ser utilizada, y muchas veces lo es, como medio para otros fines, ella siempre contiene un fin propio: la negación de la alteridad humana ${ }^{43}$. La violencia es una negación ética de la alteridad humana porque existe como acto intencional con finalidad propia.

\section{$I$}

La pulsión agresiva, que es natural, no necesariamente tiene que desembocar en violencia. Las pulsiones agresivas de la naturaleza humana pueden ser significadas de varias formas y direccionadas para otros fines como la superación de dificultades, los estímulos para vencer problemas, la firmeza para aguantar contrariedades, etc. ${ }^{44}$.

La violencia no es natural. Es el resultado de una determinada forma de significación de la pulsión agresiva dirigida intencionalmente la destrucción de la alteridad humana. Hay una diferencia cualitativa entre ambas, constituida por el potencial simbólico del lenguaje humano. La violencia, por definición, es un sentido intencional de la agresividad. Ella es significación intencional y por ello remite a la cultura, a los valores. Y, consecuentemente, las posibilidades de neutralizarla, con más o menos intensidad, también se localizan en la cultura y los valores. Aunque la agresividad continúa pulsando en el ser humano como potencia de su naturaleza, a él pertenece la posibilidad de resignificar esa potencia con sentidos no violentos. Al naturalizar la violencia se otorgar a las prácticas violentas una naturaleza que no tienen. Ellas pertenecen a la esfera simbólica de la cultura y no al mundo determinado de la naturaleza. Por ello, la neutralización de la violencia, contra lo que pensaba Lorenz y continúan pensando muchos neurocientíficos, puede realizarse con eficiencia a través de la constitución de nuevos valores en los que la alteridad humana sea la referencia ética de su desconstrucción.

La violencia concebida como producción de sentido pierde el carácter compulsivo con que contamina toda la relación política. La potencia política de la violencia y del miedo no advienen de la naturaleza humana sino de la fuerza simbólica que los impone.

\section{Conclusión, memoria y violencia}

La memoria, para las tendencias naturalistas, se restringe al epifenómeno de la ideología moral considerada ineficiente para neutralizar la violencia natural. Retirada la máscara del pretendido naturalismo de la 
violencia, la memoria recupera el vigor original por el cual consigue mostrar la barbarie correspondiente a toda violencia. El rostro de las víctimas, rescatado por la potencia anamnética, tiene el poder simbólico de neutralizar cualquier justificación de la violencia. La memoria contiene la potencia del sentido que trae la luz las consecuencias perversas de la violencia. La muestra pública de las perversiones que toda violencia esconde, sirve de acicate simbólico para deslegitimar su uso y neutralizar su potencia.

Las tesis que pretenden naturalizar la memoria, como lo hacen con la violencia, resultan insuficientes para explicar una y otra en el ser humano. Aquéllas también confunden dos categorías semejantes pero diferentes: recuerdo y memoria. Los recuerdos son registros vitales de hechos vividos. Estos se asocian a un potencial instinto de vida. Todos los seres vivos tienen registros de lo vivido, en mayor o menor grado, lo que les permite recordar. El recuerdo está asociado a mecanismos vitales, neuronales, instintivos y genéticos de la especie en cada individuo. Sin embargo, hay una diferencia cualitativa entre el recuerdo y la memoria ${ }^{45}$. Si aquél está vinculado al instinto y la genética de la especie que registra los hechos, la memoria es la construcción de sentido para los hechos vividos. Lo específico de la memoria es el sentido. La memoria reconstruye los recuerdos con uno o varios sentidos. La memoria instituye el sentido de los recuerdos. La memoria es una producción significativa de sentido para las experiencias vividas. Ella no es instintiva, sino simbólica y cultural. El recuerdo es vital, la memoria es humana.

La memoria es una creación de sentido. Ella no puede ser inducida ni deducida de la objetividad de los recuerdos ni de la materialidad biológica ${ }^{46}$. La memoria excede ambos, transciende la compulsividad de los instintos rehaciéndola en forma de narrativa de sentido. La memoria construye las narrativas de las vivencias, tales narrativas, aunque tienen apoyo en la base instintiva y biológica de la capacidad de recordar, no puede reducirse o deducirse de ella. La narración de la memoria es creación simbólica de sentido. Por ello la memoria se torna un campo de disputa (bio)política de sentidos que no puede ser reducido a objeto científico de las pulsiones. La memoria que neutraliza la violencia, sufre la amenaza biopolítica de ser reducida a mero recuerdo. Vaciada del sentido, queda reducida a un registro biológico. Impregnada de significaciones recobra el vigor de neutralizar la violencia.

\section{NOTAS}

\footnotetext{
1 Hay que registrar la divergencia teórica entre Foucault e Agambem sobre la amplitud histórica de la biopolítica. En tanto que Foucault remarca en sus estudios genealógicos la ruptura biopolítica de la modernidad, Agamben refuerza la tesis del carácter biopolítico de la política y el derecho desde sus orígenes. Ambos coinciden en que la modernidad, a través del Estado y el mercado, expandió la biopolítica de forma hegemónica por el conjunto de las instituciones sociales. Cf. Foucault, Michel, Sécurité, territoire, population, Paris, Seuil/Gallimard, 2004; Id., Il fout defender la societé, Paris, Seuil, 1997; Agambem, Giorgio, Homo sacer. O poder soberano e a vida nua, Belo Horizonte, UFMG, 2002.
}

2 Hannah Arendt sustenta la tesis de que la vida humana es inherente al origen de la política. Aun sin mencionar en sus estudios el concepto de biopolítica, sus análisis recolocan la vida como la categoría central de la política desde sus orígenes: «Además, como la acción es la actividad política por excelencia, la natalidad, y no la mortalidad, puede ser la categoría central del pensamiento político, en contraposición al pensamiento metafísico». Id., A condição humana, São Paulo, Forense Universitária, 2010, p. 10.

3 Aunque Hobbes fue muy criticado por su propuesta autoritaria, su paradigma naturalista continua siendo un marco de la biopolítica moderna en muchos aspectos. Hobbes es el autor que ejemplifica el giro 
moderno en el que la vida es capturada como categoría política. En su caso, siguiendo el modelo mecanicista de naturaleza propio del siglo XVII, explora las conexiones causales entre naturaleza humana y sociedad. Este tema ya clásico en Hobbes fue tratado por muchos autores, entre otros, cf. Zarka, Charles Yves, La Décision Métaphysique de Hobbes, Paris, Librairre-philosophique J. vrin, 2001; Zarka, Yves Charles, Hobbes et la Pensé Politique Moderne, Paris, PUF, 2001; Zarka, Yves Charles y Skinner, Quentin, Deux interpretations de Hobbes e Actualité de Hobbes, Le Débat, 96, 1997; Strauss, Leo, Natural Right and History, Chicago, University of Chicago Press, 1990; Strauss, Leo, The Political Philosophy of Thomas Hobbes - Its Basis and Genesis, Chicago, University of Chicago Press, 1963.

${ }^{4}$ Hobbes deja explícita esta tesis en la introducción de su obra, Leviatán. «La naturaleza, arte por el que Dios ha hecho y gobierna el mundo, es imitada por el arte del hombre, como en tantas otras cosas, en que este puede fabricar un animal artificial (...) Pero el arte va aún más lejos, llegando a imitar esa obra racional y máxima de la naturaleza: el hombre. Pues es mediante el arte como se crea ese gran LEVIATAN que llamamos REPÚBLICA o ESTADO, en latín CIVITAS, y que no es otra cosa que un hombre artificial.» Hobbes, Thomas, Leviatán, Madrid, Altaya, 1997, p. 13

5 Foucault definió con un aforismo ya célebre esta paradoja que vincula la vida de forma diferente al poder soberano y al gobierno moderno. El poder soberano puede definirse, como aquél que: «tiene el derecho de hacer morir y dejar vivir» en cuanto el gobierno moderno se caracteriza por: «hacer vivir y dejar morir». Foucault, Michel, «Direito de morte e poder sobre a vida», en Id., História da sexualidade 1. Vontade de poder, Rio de Janeiro, Graal, 1999, pp. 128-130.

6 Adorno e Horkheimer apuntaron y desarrollaron esta temática en varios momentos. Sus conceptos de racionalidad instrumental y sociedad administrada, entre otros, reflejan el proceso totalizador que se abatió sobre la vida humana una vez reducida a mero objeto de gobierno: "El pensamiento se vuelve un mero órgano rebajado a naturaleza. Para los gobernantes, sin embargo, los hombres se convierten en una especie de material, como lo es la naturaleza entera para la sociedad». Id., Dialética do esclarecimento. Excurso II, Rio de Janeiro, Zahar, 2006, pp. 75-76.

7 La obra de Spinoza, contemporánea de Hobbes, también comparte el paradigma naturalista del comportamiento humano, llevado a su extremo en el radical inmanentismo que determina la conducta de las personas. Paradójicamente, su propuesta política tiende a un republicanismo ético, que se distancia del poder absoluto propuesto por Hobbes. «Porque, al final, todos los hombres, bárbaros o civilizados establecen en todas las partes costumbres y se dan un estatuto civil, no es de las enseñanzas de la Razón, sino de la naturaleza de los hombres, o sea, de su condición na- tural que se debe deducir las causas y los fundamentos naturales de los poderes públicos». Spinoza, Baruch, Tratado político, Rio de Janeiro, Nova Cultural, 1999, p. 441.

8 Hobbes, Thomas, Do cidadão, São Paulo, Martin Fontes, 2002, p. 28.

${ }^{9}$ La crítica al pretendido naturalismo de la competición natural como principal causa natural de la evolución fue ampliamente descrita por Kroptkin, Peter, Mutual Aid, London, 1902, que en sus investigaciones como naturalista constató que la ayuda mutua se tornó un factor esencial para la supervivencia de las especies, para su mejor adaptación y superación de dificultades. Tesis defendida en la Real Academia Inglesa de Ciencias Naturales (la misma que aprobó las tesis de Darwin) y por ella aprobadas. Sobre la crítica al naturalismo de Darwin también, cf. Montagu, Ashley, La naturaleza de la agresividad humana, Madrid, Alianza Editorial, 1985.

10 Aunque desde otro ángulo, la problemática de la relación instituyente de la violencia y el derecho es el eje temático del clásico texto de Walter Benjamín, que desde la perspectiva jurídica presenta el debate sobre las consecuencias, fatales, de la violencia inmanente al derecho. Benjamin, Walter, Por uma crítica da violência, São Paulo, Ed. Cultrix, 1986, pp. 160-175. En algunos aspectos mantenemos un distanciamiento crítico del naturalismo que Benjamín otorga a la violencia en su relación con el derecho. Sobre este punto, cf. Bartolomé Ruiz, Castor M. M., «A justiça perante uma crítica ética da violência», en Id., Justiça e memória. Por uma crítica ética da violência, São Leopoldo, Unisinos, 2009, pp. 83-117.

11 Lorenz, Konrad, Sobre la agresión: el pretendido mal, México, Siglo XXI, 1974. Sobre el autor conferir también Lorenz, Konrad, Natural Science of The Humans Species, Nova York, Mit Press, 1966.

12 «¿Porque luchan los seres vivos unos contra los otros? La lucha es un proceso sempiterno en la naturaleza, y las pautas de comportamiento, así como las armas defensivas que les sirven, están perfeccionadas y se han formado tan claramente obligadas por la presión selectiva de su función conservadora de la especie que sin duda tenemos la obligación de plantear la cuestión darwiniana». Lorenz, Konrad, op. cit., p. 3.

13 Lorenz, Konrad, op. cit., p. 265.

14 Lorenz, Konrad, op. cit., pp. 124-157.

15 Lorenz, Konrad, op. cit., p. 263.

16 Wilson, Edward, Sociobiología. Una nueva sintesis, Buenos Aires, Ómega, 1975.

17 Wilson, Edward, op. cit., p. 78.

18 Wilson disiente de la distinción cualitativa de Lorenz entre violencia intra-específica e inter-específica. Para este autor la violencia, siendo un instinto natural, es adaptativo. Hay muchas variables que entran como componentes de la conducta agresiva de cada especie. La función adaptativa de la violencia requiere un complejo juego de jerarquías, estrategias, territo- 
rios, adaptaciones, etc. Wilson, Edward, op. cit., p. 127.

19 Dawkins, Richard, O Gene Egoísta, Belo Horizonte, Editora Itatiaia, 2001. También cf. Dawkins, Richard, A grande história da evolução, São Paulo, Companhia das letras, 2009.

20 Dawkins, Richard, op. cit., p. 22.

21 Dawkins, Richard, op. cit., p. 78.

22 Dawkins, Richard, op. cit., p. 215.

23 «somos construidos como máquinas génicas y cultivados como máquinas mémicas, pero tenemos el poder de rebelarnos contra nuestros criadores. Solamente nosotros en la tierra podemos rebelarnos contra la tiranía de los replicadores egoístas». Dawkins, Richard, op. cit., p. 222.

24 Damásio, Antonio, O Erro de Descartes, São Paulo, Companhia das Letras, 1996; Id., Em Busca de Espinosa, São Paulo, Companhia das Letras, 2003.

25 Damásio, Antonio, O Erro de Descartes, São Paulo, Companhia das Letras, 1996, pp. 36ss.

26 Arendt, Hannah, Sobre la violencia, Madrid, Alianza ed., 2005.

27 Arendt, Hannah, p. 79.

28 Arendt, Hannah, p. 100.

29 Arendt, Hannah, p. 94

30 Arendt, Hannah, p. 61.

31 Arendt, Hannah, p. 62. Esta misma concepción de autoridad es desarrollada por la autora más ampliamente en Id., «¿Qué es autoridad?»; en Id., Entre el pasado y el futuro, Barcelona, Península, 2003, pp. $145-226$.

32 Arendt, Hannah, p. 112

33 Arendt, Hannah, p. 57.

34 «Poder corresponde a la capacidad humana, no simplemente de actuar, sino de actuar concertadamente. El poder nunca es propiedad de un individuo, pertenece a un grupo y sigue existiendo mientras el grupo se mantenga unido». Arendt, Hannah, p. 60.

35 Arendt, Hannah, p. 71.

36 Arendt, Hannah, p. 72.

37 Arendt, Hannah, p. 63.

38 En este punto marcamos una cierta discordancia con la opinión de Agamben sobre: «las penetrantes indagaciones que Hannah Arendt dedicó en la posguerra a la la estructura de los Estados totalitarios tiene un límite, la falta de cualquier perspectiva biopolítica». Id., Homo Sacer. O poder soberano e a vida nua, Belo Horizonte, UFMG, 2002, p. 126. Tal crítica ha de ser complementada con el análisis de otros textos, como el que estamos proponiendo.

39 «De la misma manera que en el reino de la vida orgánica todo crece y decae, se supone que en el reino de los asuntos humanos, el poder puede sustentarse a si mismo sólo a través de la expansión; de otra mane$\mathrm{ra}$, se reduce y muere». Arendt, Hannah, op. cit., p. 101.

40 En el ámbito de los estudios de antropología general, la obra mencionada anteriormente de Ashley Montagu, La naturaleza de la agresividad humana. Madrid, Alianza Ed., 1985, hace severas críticas a la teoría del instinto agresivo de Lorenz. Según A. Montagu, Lorenz provoca un reduccionismo antropológico que somete el ser humano al destino inexorable de la violencia natural, no teniendo en cuenta que la integración y la colaboración solidaria con otros individuos es un instinto básico de todas las especies vivas, que en algunas se transformó en el instinto predominante. Para Montagu, en los seres vivos no sólo existe el instinto agresivo sino también hay el instinto natural de la colaboración solidaria. Montagu, A., op. cit., pp. 44-53.

41 Sobre la dimensión simbólica del ser humano remitimos, entre otros, a los estudios de Cassirer, Ernst, Filosofía de las formas simbólicas, 3 vols., México, FCE, 1998; Id., Antropologia filosófica, São Paulo, Martin Fontes, 2007.

42 Sobre el poder creador de significaciones y simbolismo del ser humano ver también. Castoriadis, Cornelius, A instituição imaginária da sociedade, São Paulo, Paz e Terra, 1991.

43 En este punto divergimos de Hannah Arendt que tiende a conferir a la violencia un carácter de mero medio instrumental sin fines propios. Id., op. cit., pp. 63ss.

44 Esta posición es defendida por Herbert Marcuse en su ensayo La agresividad en la sociedad industrial avanzada. Para Marcuse, la transformación de la energía agresiva del Thanatos en potencia constructiva es el proceso realizado por la sublimación. Marcuse, Herbert, La agresividad en la sociedad industrial avanzada, Madrid, Alianza Editorial, 1971, p. 112.

45 Los memes inherentes a todo ser vivo, diagnosticados por Dawkins, pueden ser interpretados como recuerdos, potencia de recordar. Pero ellos no son memoria porque les falta la producción de sentido para los recuerdos, algo genuinamente humano. Dawkins, Richard, op. cit., p. 222.

46 Además de los autores mencionados en este ensayo, son conocidas las críticas de Nietzsche a la memoria y su tesis sobre el origen biológico de la misma como freno a la violencia auto-destructiva de la especie. Nietzsche, Friedrich. «Considerações extemporâneas II», São Paulo, Abril Cultural, 1987; Nietzsche, Friedrich, La genealogia de la moral, Bogotá, Thema, 2003. 